\title{
KUALITAS PELAYANAN BIDANG PENDIDIKAN DASAR DI KECAMATAN KULISUSU KABUPATEN BUTON UTARA
}

\author{
${ }^{1}$ La Mudae, ${ }^{2}$ Jopang, ${ }^{3}$ Nana Mulyana \\ 1 Program Pascasarjana Administrasi Publik Universitas Terbuka \\ 2Jurusan IImu Administrasi Publik Universitas Halu Oleo \\ ${ }^{3}$ PPs Universitas Pasundan Bandung \\ Corespondence email: amudaekampung@gmail.com
}

\begin{abstract}
The purpose of this study was to determine and analyze the quality of services in the field of basic education in Kulisusu District, North Buton Regency. This study uses a descriptive qualitative approach. There were 11 research informants consisting of the Head of the Education and Culture Office, Head of the GTK Division of the Education and Culture Office, Head of SD Lamoahi, Head of SD Lelamo, Head of SDN Wa Ode Buri, 3 teaching staff and 3 Committee Chairs. The selection of informants was done purposively. Data were collected through observation, interviews and document studies. The data collected was then analyzed descriptively qualitatively.

The results showed that the quality of service in the field of basic education in Kulisusu District, North Buton Regency was not optimal. This can be seen from the 10 dimensions measured, indicating that the indicators of tangible, credibility, competent, reliable and security are not yet optimal and still require serious improvement. Meanwhile, indicators of access, courtersy, competent, responsiveness, communication, and understanding of the customer have been well fulfilled.
\end{abstract}

\section{Keywords: Basic Education; Service; Quality}

\begin{abstract}
Abstrak
Tujuan penelitian ini adalah untuk mengetahui dan menganalisis kualitas pelayanan bidang pendidikan dasar di Kecamatan Kulisusu Kabupaten Buton Utara. Penelitian ini menggunakan pendekatan kualitatif deskriptif. Informan penelitian sebanyak 11 orang terdiri dari Kepala Dinas Pendidikan dan Kebudayaan, Kepala Bidang GTK Dinas Pendidikan dan Kebudayaan, Kepala SDN 1 Lamoahi, Kepala SDN 1 Lelamo, Kepala SDN 1 Wa Ode Buri, 3 orang tenaga pengajar dan 3 orang Ketua Komite. Pemilihan informan dilakukan secara purposive. Data dikumpulkan melalui observasi, wawancara dan studi dokumen. Data yang dikumpulkan selanjutnya dianalisis secara kualitatif deskriptif.

Hasil penelitian menunjukkan kualitas pelayanan bidang pendidikan dasar di Kecamatan Kulisusu Kabupaten Buton Utara belum optimal. Hal ini dapat dilihat dari 10 dimensi yang diukur, menunjukkan bahwa indikator tangible (terlihat), credibililty (kredibilitas), competent (kompeten), reliable (kehandalan) dan security (keamanan) belum optimal dan masih memerlukan pembenahan serius. Sedangkan indicator access (akses), courstersy (sikap ramah dan bersahabat), competent (kompeten), responsivinnes (respon cepat), communication (komunikasi) dan understanding the customer (berorientasi pelanggan) telah terpenuhi dengan baik.
\end{abstract}

Kata Kunci: Kualitas; Pelayanan; Pendidikan Dasar 


\section{Journal Publicuho}

ISSN2621-1351 (online), ISSN 2685-0729 (print)

Volume 4 Number 4 (November - January), (2021) pp. 1156-1166 Accredited SINTA SK.NOMOR 28/E/KPT/2019 Open Access at:http://ojs.uho.ac.id/index.php/PUBLICUHO/index $\quad$ DOl: http://dx.doi.org/10.35817/jpu.v4i4.21956

\section{PENDAHULUAN}

Sejak mekar dari Kabupaten Muna, pada tahun 2007 Pemerintah Kabupaten Buton Utara terus melaksanakan penataan pelayanan bidang pendidikan. Pelayanan bidang pedidikan merupakan faktor penting dalam sistem pemerintahan. Oleh karena itu banyak anggaran yang di berikan oleh pemerintah daerah untuk memberikan pelayanan bidang pendidikan. Namun besarnya anggaran yang diberikan belum sebanding dengan hasil yang dicapai dalam pelaksanaan pelayanan bidang pendidikan khususnya pelayanan bidang pendidikan dasar. Lemahnya pelayanan bidang pendidikan dasar erat kaitannya dengan terbatasnya sumber daya manusia. Berdasarkan data referensi Kementerian Pendidikan dan Kebudayaan RI yang dimuat dalam situs https://referensi.data.kemdikbud.go.id/ merilis di Kabupaten Buton Utara terdapat 79 Sekolah Dasar terdiri dari 77 Sekolah Dasar Negeri yang tersebar pada 6 (enam) kecamatan (Pusdatin, 2019).

Berdasarkan data Badan Akreditasi Nasional (BAN) Sekolah Propinsi Sultra (2019) terdapat 77 unit SD Negeri, terdapat 6 Unit SD Negeri (7,79\%) mendapatkan akreditasi A, 35 Unit SD Negeri $(45,45 \%)$ mendapatkan akreditasi B, 27 Unit SD Negeri $(35,06 \%)$ mendapatkan akreditasi C dan sisanya 9 Unit SD Negeri $(11,68 \%)$ belum terakreditasi. Sebanyak 77 Unit SD Negeri tersebut, 12 SD Negeri diantaranya tersebar di Kecamatan Kulisusu Utara. Hasil Observasi awal peneliti tanggal 15 Desember 2020, Dari 12 unit SD Negeri tersebut memiliki akreditasi yang berbeda-beda, yaitu 2 unit SD Negeri $(16,7 \%)$ terakreditasi A, 4 Unit SD Negeri $(33,3 \%)$ terakreditasi B dan 6 Unit SD Negeri $(50 \%)$ terakreditasi C. Selain akreditasinya berbeda, kondisi geografis, sosial budaya dan ekonomi Desanya juga berbeda setiap Desa.

Hasil Survey Larisu, dkk (2019) menunjukan bahwa pelayanan pendidikan pada Diknas Pendidikan Kabupaten Buton Utara mendapat nilai C. Data tersebut menunjukkan bahwa belum optimalnya perolehan pelayanan pendidikan melalui akreditasi institusi sebagai gambaran pelayanan pendidikan dasar yang belum memuaskan. Indeks kepuasan masyarakat terhadap mutu pelayanan Dinas Pendidikan Kabupaten Buton Utara memperoleh nilai $C$ (kurang). Hal ini mengandung makna bahwa pelayanan bidang pendidikan di Kabupaten Buton Utara masih butuh pembenahan dan perbaikan.

Penelitian ini mengambil lokasi di tiga SD Negeri yang ada di Kecamatan Kulisusu Utara. 2 SD adalah sekolah yang ada di dekat ibukota Kecamatan sementara satu sekolah adalah terletak di pesisir dan cukup jauh dengan ibukota Kecamatan. SDN yang menjadi lokus penelitian adalah SDN 1 Waode Buri, SDN 1 Lelamo dan SDN 1 Lamoahi. SDN 1 Lelamo memiliki guru sebanyak 8 orang yang terdiri atas guru kelas dan guru mata pelajaran. Peserta didik pada SDN 1 Lelamo sebanyak 116 orang. Fasilitas perpustakaan di SD Negeri 1 Lelamo belum memadai, ruang perpustakaan ada namun fasilitas penunjang seperti meja 
kursi, rak buku dan fasilitas penunjang perpustakaan lainnya belum ada. SDN 1 Lelamo mendapat nilai akreditasi C. Di SDN 1 Waode Buri memiliki guru sebanyak 12 orang yang terdiri dari guru PNS sebanyak 11 orang dan guru honor sebanyak 1 orang. Jumlah peserta didik pada SDN 1 Waode Buri sebanyak 184 peserta didik yang terdiri atas 8 rombongan belajar. Perpustakaan dan WC sekolah belum memadai. SDN 1 Waode Buri mendapatkan nilai akreditasi $B$.

Jumlah Guru pada SDN 1 Lamoahi sebanyak 6 orang. SDN 1 Lamoahi terletak di pesisir utara pulau Buton dan posisinya berada dipesisir pantai. Letaknya dari ibukota Kecamatan Kulisusu Utara sangat jauh dan akses jalan menuju Desa Lamoahi belum memadai. SDN 1 Lamoahi mendapatkan akreditasi C dan nilai perolehan akreditasi adalah 72. Berdasarkan pada uraian di atas, pelayanan pendidikan khususnya pendidikan dasar belum maksimal. Parasuraman, Berry dan Zeithami dalam Tjiptono (2008) menyatakan kualitas pelayanan didasarkan dimensi kehandalan, kompeten, kredibel, bukti fisik, sopan santun, keamanan, akses, komunikasi dan berorientasi pada pelanggan

Pelayanan publik dapat didefinisikan sebagai serangkaian aktifitas yang dilakukan oleh birokrasi publik untuk memenuhi kebutuhan warga pengguna (Dwiyanto, 2008). Merujuk pada pandangan yang dikemukakan oleh Dwiyanto maka terkait dengan pendidikan dasar, layanan pada pelaksanaan pendidikan dasar di Kabupaten Buton Utara merupakan rangkaian aktifitas yang dilakukan oleh birokrasi publik untuk memenuhi kebutuhan warga pengguna. Warga pengguna layanan pada pendidikan dasar dan menengah belum berjalan maksimal. Masih ada oknum birokrat yang belum memahami tupoksinya dalam menjalankan tugasnya. Sejatinya para birokrat sudah harus memahami apa yang menjadi tugas pokok dan fungsi yang melekat pada diri birokrat sehingga pelayanan publik yang akan mereka laksanakan bisa dirasakan manfaatnya oleh para pengguna. Berdasarkan pada apa yang telah diuraikan di atas terkait dengan pelayanan publik maka yang menjadi pertanyaan penelitian pada penelitian ini adalah "Bagaimanakah Pelayanan Publik Bidang Pendidikan Dasar di Kecamatan Kulisusu Utara".

\section{METODOLOGI}

Penelitian ini dilaksanakan di SD Negeri Lamoahi, SDN 1 Wa Ode Buri dan SDN 1 Lelamo di Kecamatan Kulisusu Utara. Pemilihan sekolah tersebut dilakukan secara purposive dengan pertimbangan : (1). SDN 1 Wa Ode Buri terakreditasi A, SDN 1 Lamoahi terakreditasi B dan SDN 1 Lelamo terakrditasi C. (2). Sarana dan prasarana di SDN 1 Lelamo belum memadai, jika dibandingkan dengan SDN 1 Lamoahi. Sedangkan SDN 1 Wa Ode Buri lebih memadai jika dibandingkan dengan SDN 1 Lamoahi. Demikian juga dengan jumlah guru. Jumlah Guru SDN 1 Wa Ode Buri sudah memadai jika dibandingkan dengan SDNi 1 Lamoahi dengan SDN 1 Lelamo. Penelitian ini menggunakan pendekatan kualitatif. Informan penelitian sebanyak 11 orang terdiri dari Kepala Dinas Pendidikan dan Kebudayaan, Kepala Bidang GTK Dinas 


\section{Journal Publicuho}

ISSN2621-1351 (online), ISSN 2685-0729 (print)

Volume 4 Number 4 (November - January), (2021) pp. 1156-1166 Accredited SINTA SK.NOMOR 28/E/KPT/2019 Open Access at:http://ojs.uho.ac.id/index.php/PUBLICUHO/index $\quad$ DOl: http://dx.doi.org/10.35817/jpu.v4i4.21956

Pendidikan dan Kebudayaan, Kepala SDN 1 Lamoahi, Kepala SDN 1 Lelamo, Kepala SDN 1 Wa Ode Buri, 3 orang tenaga pengajar dan 3 orang Ketua Komite. . Penentuan informan dilakukan secara purposive. Data dikumpulkan melalui metode wawancara dan studi dokumen. Analisis Data dilakukan melalui model interaktif Milles dan Huberman (2004) terdiri dari pengumpulan data, penyajian data, reduksi data dan penarikan kesimpulan.

\section{HASIL DAN PEMBAHASAN}

\section{Tangible (terlihat/terjamah)}

Pelaksanaan layanan, terutama dalam bidang pendidikan dasar hal terpenting yang harus diperhatikan adalah aspek tangible (terlihat/terjamah) terdiri atas fasilitas fisik, peralatan, personil dan komunikasi. Hasil studi terhadap fasilitas fisik seperti gedung sekolah, kantor, perpustakaan, ketersediaan halaman menunjukkan bangunan sekolah, kantor, perpustakaan, toilet, halaman sekolah, taman bunga, areal parker dan ruang tunggu secara fisik tersedia. Kondisi gedung sekolah, kantor dan perpustakaan di tiga sekolah yang diamati masih dalam kondisi baik. Kondisi toilet di SD Negeri 1 Wa Ode Buri tersedia dengan baik. Toilet siswa dan guru terpisah. Berbeda dengan di SD Negeri 1 Lelamo dan SD Negeri 1 Lamoahi secara fisik terdapat toilet namun kondisinya sangat kotor dan tidak dapat difungsikan dengan baik. Hanya ada 1 toilet khusus guru, namun tidak dapat digunakan oleh siswa, sehingga kebanyak siswa saat membuang air kecil ataupun tinja harus pergi di luar areal sekolah. Kondisi pagar sekolah di tiga sekolah sudah ada sebagian, hanya pada bagian depan. Bagian samping dan belakang sekolah belum dipagari, sehingga belum memberikan kenyamanan bagi guru dan siswa di sekolah tersebut. Ketersediaan halaman dan penataannya di tiga sekolah sudah lumayan bagus. SD Negeri 1 Wa Ode Buri memiliki luas halaman 400 m2, dengan area parkir 120 m2. Pada bagian halaman yang tertata dengan taman bunga yang cukup rapi sehingga menambah keindahan sekolah tersebut. Demikian pula di SD negeri 1 Lamoahi, memiliki luas halaman $320 \mathrm{~m} 2$, dengan areal parker 90 m2 serta tanaman bunga yang tertata rapi sehingga sekolah tersebut kelihatan indah. Kondisi yang berbeda dengan SD Negeri 1 Lelamo memiliki halaman yang tidak terlalu luas yaitu sekitar 250 m2, namun tidak memiliki areal parkir secara khusus, namun sekolah tersebut memiliki taman bunga yang cukup indah dengan berbagai jenis bunga. Sementara dari aspek sarana pendukung seperti computer dan jaringan internet di tiga sekolah yang diteliti masih belum ada, termasuk operatornya juga belum tersedia dengan baik. Selama ini sekolah mengandalkan rental yang ada di pusat Kecamatan Kulisusu Utara.

Ketersediaan peralatan pembelajaran di SDN 1 Wa Ode Buri tersedia dengan baik, seperti buku-buku pelajaran, alat-alat olahraga (bola volley, bola kaki, net, lapangan volley dan tenis meja), termasuk beberapa alat peraga lainnya. Sementara di SDN 1 Lamoahi dan 
SDN 1 Lelamo alat-alat pembelajaran seperti buku juga tersedia dengan baik, namun alatalat peraga pembelajaran kondisinya sudah rusak.

Ketersediaan personil di SDN 1 Wa Ode Buri terbilang cukup baik, sebab guru dan pegawai tersedia sesuai dengan kebutuhan sekolah, terdiri dari 6 orang guru kelas, 1 orang guru agama, 1 orang guru olahraga, 1 orang kepala sekolah dan 1 orang penjaga sekolah. Di SDN 1 Lamoahi guru kelas hanya 3 orang, 1 orang guru agama, 1 orang kepala sekolah dan 1 penjaga sekolah, 2 orang guru honorer yang mengajar mata pelajaran olahraga dan sebagai guru kelas. Demikian juga dengan di SDN 1 Lelamo hanya terdiri dari 2 orang guru kelas serta 1 orang kepala sekolah dan penjaga sekolah. Di sekolah ini juga terdapat 3 orang guru honorer. Komputer telah tersedia di tiga sekolah tersebut, namun jaringan internet belum ada sehingga fasilitas pembelajaran online dan pelaksanaan tugas-tugas lainnya yag menggunakan jaringan masih terbatas. Tiga sekolah yang diamati juga telah memiliki jaringan listrik.

Berdasarkan deskripsi aspek kehandalan layanan bidang pendidikan dasar di tiga sekolah yang diukur menunjukkan hasil yang belum optimal, terutama ketersediaan toilet, pagar sekolah, peralatan pembelajaran, dan jaringan internet. Tjiptono (2008) menyebutkan kualitas pelayanan yang didasarkan pada bukti langsung yaitu kelengkapan pelayanan yang bisa dilihat/dirasakan secara langsung oleh pelanggan. Kehandalam layanan publik tercermin pada fasilitas fisik, peralatan, personil dan bahan komunikasi (Parasurahman, dkk., 2008). Kehandalan layanan memberikan kenyamanan bagi pengguna layanan dan petugas layanan. Matul and Tsilikounas (2004) menyebutkan kondisi fisik pelayanan memberikan apreseasi dan image positif bagi pengguna layanan.

\section{Realiable (kehandalan),}

Reliabel (kehandalan) terdiri dari kemampuan unit pelayanan dalam menciptakan pelayanan yang dijanjikan dengan tepat. Pelayanan dasar seperti pengurusan legalisir ijazah, bantuan pendidikan, laporan pelaksanaan pendidikan dan layanan ijazah di SDN 1 Wa Ode Buri sudah terlaksana dengan baik. Hasil wawancara dengan informan memberikan respon postif terhadap kemampuan pelayanan yang diberikan oleh sekolah. Berbeda dengan SDN 1 Lamoahi dengan SDN Lelamo, aspek kehndalan layanan yang diberikan masih lambat, selalu tertunda sehingga respon negative pengguna mewarnai penilaian yang diberikan kepada petugas layanan di dua sekolah tersebut. Belum ditemukan jenis dan standar prosedur layanan yang diberikan. Tidak tersedianya operator untuk mengoperasikan computer serta keterbatasan jaringan menyebabkan layanan di sekolah lokasi studi belum optimal. Padahal kehandalan layanan sangat mennentukan kualitas dan kepuasan terhadap layanan yang diberikan. Moenir (2006) dalam Raharjo (2013) layanan adalah proses pemenuhan kebutuhan melalui aktivitas orang lain secara langsung. 


\section{Journal Publicuho}

ISSN2621-1351 (online), ISSN 2685-0729 (print)

Volume 4 Number 4 (November - January), (2021) pp. 1156-1166 Accredited SINTA SK.NOMOR 28/E/KPT/2019 Open Access at:http://ojs.uho.ac.id/index.php/PUBLICUHO/index $\quad$ DOl: http://dx.doi.org/10.35817/jpu.v4i4.21956

\section{Responsiveness (daya tanggap),}

Responsiveness (daya tanggap) adalah kemauan untuk membantu konsumen bertanggungjawab terhadap kualitas pelayanan yang diberikan. Hasil studi menunjukkan adanya respon yang cepat terhadap layanan yang diberikan kepada pengguna layanan. Selain itu petugas layanan guru dan kepala sekolah di tiga sekolah yang ada senantiasa berlangsung dengan cepat dan cermat. Hampir semua keluhan terhadap jenis layanan yang diberikan direspon dengan cepat oleh pihak sekolah. Hal ini disampaikan oleh Ketua Komite SDN 1 Wa Ode Buri, Ketua Komite SDN 1 Lamoahi dan Tokoh Masyarakat di Desa Lelamo. Pernyataan senada juga disampaikan oleh Kepala Bidang GTK Dinas Pendidikan dan Kebudayaan Kabupaten Buton Utara bahwa dalam upaya pemberian layanan kepada siswa, alumni dan stakeholdrs lainnya ditekankan kepada pihak sekolah agar memberikan layanan yang cepat, tepat, cermat dan tidak berbelit-beliit.

Berdasarkan deskripsi yang diuraikan tersebut menunjukkan bahwa pelayanan dengan indicator responsiveness (tanggap) di SD Kecamatan Kulisusu Barat telah terlaksana dengan baik. Hal ini sejalan dengan Zeithaml dkk., (2000) dalam Sitorus (2009) responsiveness merupakan kemauan atau keinginan para karyawan untuk membantu dan memberikan jasa yang dibutuhkan konsumen. Respon yang baik akan menimbulkan kesan positif bagi pengguna layanan, sebaliknya respon yang lambat dan kurang baik akan menimbulkan kesan negative bagi pengguna sehingga mereka merasakan ketidakpuasan dalam pelayanan.

\section{Competent (Kompeten)}

Kompeten merupakan tuntutan yang dimiliki oleh petugas layanan berupa pengetahuan dan ketrampilan yang baik dalam memberikan layanan. Hasil studi menunjukkan bahwa pelayanan pendidikan di SDN 1 Wa Ode Buri telah berlangsung dengan baik karena didukung oleh tenaga yang komopten. Tenaga kompoten dimaksud adalah guru, kepala sekolah dan pejaga sekolah. Sebanyak 9 orang guru yang ada semua sudah mempunyai latar belakang Sarjana Pendidikan dan Sarjana Olahraga dan Sarjana Agama, sehingga pelayanan yang diberikan kepada siswa, orang tua dan stakeholders lainnya diakses dengan cepat. Kondisi berbeda dengan SDN 1 Lelamo dan SDN 1 Lamoahi belum optimal. Hal ini disebabkan oleh adanya keterbatasan tenaga yang ada. Pelayanan belum maksimal disebabkan oleh pelayanan dilakukan oleh guru honorer, serta guru-guru mayoritas sudah berusia di atas 50 tahun sehingga proses pembelajaran dan jenis lainnya tidak maksimal. Hal ini disampaikan oleh Kepala Sekolah pada saat wawancara di ruang kerja kepala sekolah. Kondisi ini berdampak juga pada rendahnya mutu pendidikan di Sekolah tersebut. Akreditasi Sekolah tahun 2018 menunjukkan nilai B untuk SDN 1 Lamoahi dan Akreditasi C pada SDN 1 Lelamo. 
Berdasarkan deskripsi di atas menunjukkan bahwa pelayanan dengan indicator competent (kompeten) belum optimal. Rendahnya mutu hasil pekerjaan dan pelayanan kepada masyarakat dapat merupakan akibat tingkat pengetahuan dan keterampilan yang minim. (Nurdin, 2019). Pelayanan yang baik didukung oleh SDM yang kompeten sebagai penggerak teknologi untuk mendukung palayanan (Masdar, dkk., 2009).

\section{Courtesy (Sikap Ramah dan bersahabat)}

Sikap atau perilaku ramah, bersahabat, tanggap terhadap keinginan konsumen serta mau melakukan kontak atau hubungan pribadi. Hasil studi menunjukkan bahwa perilaku ramah telah ditunjukkan oleh guru, kepala sekolah dan pegawai di tiga sekolah yang diamati. Pelayanan yang diberikan telah mencerminkan ketercapaian dalam indicator Courtesy. Kepala Sekolah di lokasi studi telah membangun kerjasama dengan baik antara siswa, komite sekolah dan pihak lain. Hal ini diampaikan oleh Ktua Komite SD Negeri 1 Wa Ode Buri yang juga sejalan dengan pernytaan Ketua Komite SD Negeri 1 Lamoahi yang menjelaskan Kepala sekolah dan tenaga pengajar dalam menjalankan tugas pelayanan pendidikan dasar melakukan pendekatan-pendekatan dengan masyarakat maupun dengan siswa.

Berdasarkan uraian informasi di atas menunjukkan bahwa pelayanan dengan indicator Courtesy telah dilaksanakan dengan baik. Hal ini sejalan dengan Menurut Mittal dan Lassar yang dikutip oleh Hansen (2003) dalam Halim dan Suryani (2013), keramahan merupakan salah satu bentuk personalisasi yang akan membuat seseorang merasa akrab, senang, dan bersahabat. Image positif yang dimiliki oleh seseorang mendukung untuk menyampaikan informasi personal terhadap sesuatu yang dibicarakan (Hansen, 2003).

\section{Credibility (Kredibilitas)}

Kredibilitas adalah sikap jujur dalam setiap upaya untuk menarik kepercayaan masyarakat. Sukses tidaknya pelayanan pendidikan dasar di SD Negeri 1 Wa Ode Buri, SD Negeri 1 Lelamo dan SD Negeri 1 Lamoahi sangat ditentukan oleh kredibilitas guru, kepala sekolah maupun pegawai yang ada di dalamnya. Jika krdibitasnya baik maka pengguna layanan akan percaya dan senang dengan satuan pendidikan tersebut, sebaliknya jika satuan layanan pendidikan tersebut tidak menunjukkan adanya kredibitias yang baik maka pengguna tidak lagi percaya dengan layanan yang diberikan. Hasil studi menunjukkan keredibilitas SD Negeri 1 Wa Ode Buri dan SD Negeri 1 Lelamo lebih bagus dibandingkan dengan SD Negeri 1 Lamoahi. Kurangnya tenaga pengajar di SD Negeri 1 Lamoahi menyebabkan publik tidak meyakini sekolah tersebut dapat memberikan pelayanan yang memuaskan. Zeithmal dkk (2000) mengemukakan indikator kualitas pelayanan diantaranya Credibility : yaitu sikap jujur dalam setiap upaya untuk menarik kepercayaan masyarakat. Oleh karena itu kredibilitas yang harus dibangun oleh pihak sekolah dengan cara hadir tepat waktu. 


\section{Journal Publicuho}

ISSN2621-1351 (online), ISSN 2685-0729 (print)

Volume 4 Number 4 (November - January), (2021) pp. 1156-1166 Accredited SINTA SK.NOMOR 28/E/KPT/2019 Open Access at:http://ojs.uho.ac.id/index.php/PUBLICUHO/index $\quad$ DOl: http://dx.doi.org/10.35817/jpu.v4i4.21956

Citra positif yang terbangun bagi SD Negeri 1 Wa Ode Buri dan SD Negeri 1 Lelamo mesti dipertahankan. Sebaliknya citra negative yang ada di SD Negeri 1 Lamoahi harus diperbaiki untuk menumbuhkan kembali kepercayaan publik terhadap sekolah. Berdasarkan hasil studi ini menunjukkan bahwa pelayanan dengan indicator credibility pada sekolah di Kecamatan Kulisusu Utara belum sepenuhnya optimal, masih terdapat sekolah yang belum memenuhi kriteria kredibilitas yang memberikan citra positif kepada pengguna.

\section{Security (Keamanan)}

Dalam pelaksanaan layanan bidang pendidikan dasar, hal penting yang menjadi perhatian kepala sekolah maupun oleh guru adalah terkait dengan keamanan layanan yang diberikan. Hasil studi menunjukkan bahwa secara umum kondisi lingkungan sekolah di lokasi studi cukup aman, namun dari kriteria pemenuhan rasa aman tersebut belum terpenuhi. Hal ini dapat dilihat dari kondisi pagar sekolah dari 3 sekolah yang diamati belum sepenuhnya dipagari. Pagar sekolah hanya terlihat pada bagian depan saja, namun pada sisi samping kiri dan kanan serta bagian belakang sekolah belum dipagari. Saat melakukan kunjungan di SD Negeri 1 Lamoahi banyak kotoran ternak kambing ditemukan di dalam halaman sekolah. Kondisi ini juga menyebakan ketidaknyamanan bagi murid karena pada saat pembelajaran berlangsung terkadang murid berkeliaran di luar sekolah.

Berdasarkan informasi di atas menunjukkan bahwa dari aspek security sekolah di Kecamatan Kulisusu Utara belum aman. Padahal sisi keamanan sangat penting untuk menjamin kenyamanan pengguna layanan. Zeithmal dkk (1990) mengemukakan indikator kualitas pelayanan diantaranya Security : jasa pelayanan yang diberikan harus bebas dari bahaya atau resiko. Pihak sekolah harus memastikan kemanan siswa dari kendaraan. Selain itu pihak sekolah juga harus membuat tata tertib yang mengatur perilaku siswa sehingga aman saat berada di sekolah. Suriani dan Adythya (2020) memberikan layanan kepada pengguna harus bias memberikan rasa aman.

\section{Access (Akses)}

Access, terdapat kemudahan untuk mengadakan kontak dan pendekatan. Hasil studi menggambarkan bahwa akses sekolah kepada dinas pendidikan cukup bagus, setiap rapat pelayanan dinas pendidikan selalu memberikan masukan tentang kondisi keadaan sekolah. Masukan tersebut sangat bermanfaat untuk keberlanjutan akses antara sekolah dan Diknas serta pihak-pihak lain yang berkompeten. Pihak sekolah juga membangun akses yang baik bersama dengan Komite Sekolah serta Pemerintah Desa dan Kecamatan terhadap layanan yang diberikan. .

Berdasarkan deskripsi di atas menunjukkan bahwa ketersediaan akes layanan yang diberikan oleh sekolah sudah baik. Hal ini sejalan dengan Wajib (2019) pelayanan kepada 
masyarakat merupakan suatu bentuk interaksi antara penyedia layanan dan penerima layanan.

\section{Comunnication (Komunikasi)}

Komunikasi dimaksud adalah kemauan pemberi layanan untuk mendengarkan suara, keinginan atau aspirasi pelanggan, sekaligus kesediaan untuk selalu menyampaikan informasi baru kepada masyarakat. Berdasarkan hasil wawancara menunjukkan layanan pendidikan dasar di sekolah dasar Negeri 1 Waode Buri, seklah dasar Negeri 1 Lelamo dan sekolah dasar Negeri 1 Lamoahi pihak kepala sekolah membangun komunikasi dengan pihak lain agar pelayanan yang diberikan bisa maksimal. Kenneth dan Gary dalam Umar, (2001), mengemukakan bahwa komunikasi dapat didefinisikan sebagai penyampaian informasi antara dua orang atau lebih yang juga meliputi pertukaran informasi antara manusia dan mesin. Komunikasi dalam organisasi dapat dilihat dari sisi komunikasi antar pribadi dan komunikasi organisasi. Komunikasi atau sosialisasi dalam pelaksanaan layanan pendidikan dasar di sekolah dasar Kecamatan Kulisusu Utara Kabupaten Buton Utara berjalan lancar, dan komunikasi dilaksanakan secara lansung maupun tidak langsung. Secara langsung dilaksanakan melalui rapat dan komunikasi tidak langsung dilaksanakan melalui persuratan serta WA ponsel.

Berdasarkan informasi di atas menunjukkan bahwa indicator komunikasi dalam pelaksanaan layanan telah berjalan dengan baik. Melalui komunikasi, pihak sekolah bisa menyampaikan hal-hal yang berkaitan dengan pengembangan sekolah maupun persoalan yang dihadapi sekolah serta bagaimana menyelesaikan persoalan tersebut. Widjaja (2000) mengatakan bahwa komunikasi adalah proses penyampaian gagasan, harapan dan pesan yang disampaikan melalui lambang tertentu yang mengandung arti dilakukan oleh penyampai pesan ditujukan kepada penerima pesan.

\section{Understanding The Customer (Berorientasi pelanggan)}

Berorientasi pelanggan yang dimaksud adalah melakukan segala usaha untuk mengetahui kebutuhan pelanggan. Sekolah-sekolah di Kecamatan Kulisusu Utara memberikan pelayanan yang berorientasi pada kebutuhan-kebutuhan pelanggan dalam hal ini adalah kebutuhan siswa, orang tua murid dan stake holders. Hal ini disepakati dalam rapat komite sekolah. Perencanaan anggaran dan kebutuhan sekolah disesuaikan dengan kebutuhan masyarakat. hal ini diampaikan oleh Kepala SD Negeri 1 Wa Ode Buri bahwa kepala sekolah dalam memahami keinginan siswa maupun masyarakat terkait pelaksanaan layanan pendidikan dasar melakukan rapat komite sekolah dan berkunjung kerumah orang tua siswa. Rapat komite dilakukan sebanyak 2 kali dalam setiap semester. Selain itu guruguru juga senantiasa melakukan kunjungan ke rumah orang tua murid untuk melakukan konfirmasi terkait permasalahan siswa yang ada di sekolah (Wawancara, 7 Nopember 2020). Kondisi ini juga dialami oleh SD Negeri 1 Lamoahi dan SD Negeri 1 Lelamo. 


\section{Journal Publicuho}

ISSN2621-1351 (online), ISSN 2685-0729 (print)

Volume 4 Number 4 (November - January), (2021) pp. 1156-1166 Accredited SINTA SK.NOMOR 28/E/KPT/2019 Open Access at:http://ojs.uho.ac.id/index.php/PUBLICUHO/index $\quad$ DOl: http://dx.doi.org/10.35817/jpu.v4i4.21956

Berdasarkan hal tersebut menunukkan bahwa pelayanan yang diberikan oleh sekolah di Kecamatan Kulisusu Barat sudah berorientasi pada kebutuhan pelanggan. Hal ini sejalan dengan Adhiyana (2019) yang menyebutkan beberapa keuntungan terhadap pelayanan yang berorientasi pelanggan antara lain : (a). memaksa pemberi jasa untuk dapat bertanggung jawab kepada pelanggannya; (b). mendepolitisasi keputusan terhadap pilihan pemberi jasa; (c). merancang lebih banyak inovasi; (d). Memberi kesempatan kepada orang lain untuk memilih diantara berbagai pelayanan; (e). pelanggan lebih sedikit pemborosan karena pasokan disesuaikan dengan permintaan; (f). pelanggan mendorong pelanggan untuk membuat pilihan dan mendorong pelanggan untuk menjadi pelanggan yang berkomitmen; (g). pelanggan menciptakan peluang lebih besar bagi keadilan

\section{KESIMPULAN}

Hasil penelitian menunjukkan kualitas pelayanan bidang pendidikan dasar di Kecamatan Kulisusu Kabupaten Buton Utara belum optimal. Hal ini dapat dilihat dari 10 dimensi yang diukur, menunjukkan bahwa indikator tangible (terlihat), credibililty (kredibilitas), competent (kompeten), reliable (kehandalan) dan security (keamanan) belum optimal dan masih memerlukan pembenahan serius. Sedangkan indicator access (akses), courstersy (sikap ramah dan bersahabat), competent (kompeten), responsivinnes (respon cepat), communication (komunikasi) dan understanding the customer (berorientasi pelanggan) telah terpenuhi dengan baik.

\section{REFERENSI}

Adhiyana, Marita. 2019. Pelayanan Publik yang Berorientasi pada Pelanggan. https://docplayer.info/32349518-Pelayanan-publik-yang-berorientasi-pada-pelangganoleh-marita-ahdiyana.html (diunduh tanggal 20 Juni 2021).

Dwiyanto, Agus. 2008. Mewujudkan Good Governance Melalui Pelayanan Publik. Yogyakarta: Gadjah Mada University Press.

Halim, Nisa Chairum dan Suryani, Tatik. Pengaruh Keramahan, Kredibilitas Dan Citra Karyawan Terhadap Kedekatan Karyawan Dan Kepuasan Nasabah Produk Tabungan Bank Konvensional Di Surabaya. Journal of Business and Banking. Volume 3, No. 1, pages $81-92$.

Hansen, Harvad, 2003, 'Antecedents to customer disclosing intimacy with service employees', Journal of Marketing, (17) 6 : https://www.researchgate.net/publication/240260365 Antecedents to consumers' dis closing_intimacy_with_service_employees

Larisu, Z., Jopang dan Sumadi Dilla. 2019. Survey Indeks Kepuasan Masyarakat dalam Pelayanan Publik di Kabupaten Buton Utara. Penelitian Kerjasama LPPM dan Pemerintah Daerah Kabupaten Buton Utara : Buton Utara. 
Matul, Michal and Tsillikounas, Carolina. 2004. Role of microfinance in the household reconstruction process in Bosnia and Herzegovina. Journal International Development. $\begin{array}{lllll}\text { Volume (16), Issue (3). Page } & \text { 429-466. }\end{array}$ https://onlinelibrary.wiley.com/doi/abs/10.1002/iid.1086

Nurdin. 2009. Pengaruh kecerdasan emosional terhadap penyesuaian sosial siswa di sekolah. Jurnal Administrasi Pendidikan, 09(01), p: 86-108.

Parasuraman, A., Berry, Leonard L, and Zeithaml, Valarie A. 1988, "SERVQUAL: AMultiple-ltem Scale for Measuring Consumer Perceptions of Service Quality". Journal of Retailing, Vol;. 64 (Spring), pp. 12-40.

Parasuraman, A., Berry, Leonard L, and Zeithaml, Valarie A. 2008. "Refinement and Reassessment of The SERVQUAL Scale". Journal of Retailing, Vol;. 67 No. 4 (Winter), pp. $420-450$

Pusdatin. 2019. Data Referensi Kementerian Pendidikan dan Kebudayaan. Jakarta: Departemen Pendidikan dan Kebudayaan. https://referensi.data.kemdikbud.go.id/

Raharjo, Dessilia. 2013. Pengaruh Keandalan, Bukti Langsung, Daya Tanggap, Jaminan, Dan Empati Terhadap Kepuasan Anggota Koperasi Pegawai Republik Indonesia (KPRI) "Aneka Usaha" Pusat Veterinaria Farma. Jurnal Pendidikan Ekonomi. Volume (1) Nomor (3). Hal: 1-13. https://ejournal.unesa.ac.id/index.php/jupe/article/view/3626

Sitorus, Monang. 2009. Pengaruh Reliability, Responsiveness, Assurance, Empathy Dan Tangibles Terhadap Kualitas Pelayanan Publik (Studi Kasus Kantor Pelayanan Terpadu Kota Dumai). Joernal Borneo Administrator. Volume (5), Nomor (1). Hal : 1-12. http://www.samarinda.lan.go.id/jba/index.php/jba/article/view/40

Tjiptono, Fandy. 2008. Strategi Pemasaran. Yogyakarta : Andi Offset.

Umar, Husein. 2001. Riset Pemasaran dan Perilaku Konsumen. Jakarta: PT.Gramedia Pustaka

Wajib, Nurwino. 2019. Pentingnya Penjamninan Kualitas Pelayanan Publik. https://lenteratoday.com/pentingnya-penjaminan-kualitas-pelayanan-publik/ (diunduh 20 Juli 2021).

Widjaja, A.W. 2000. Ilmu Komunikasi Pengantar Studi. Jakarta: Rineka Cipta. 